\title{
Rare case of congenital granular cell tumor of mandibular alveolar ridge in the new born
}

\author{
Case Anil Kumar Raichoor ${ }^{a}$, Yogesh pal Singh ${ }^{b}$, Megha Jaiin ${ }^{a}$, Swapnali M. Gandhe \\ Report and Puja Singh ${ }^{a}$ \\ ${ }^{a}$ Department of Maxillofacial Surgery, Chhindwara Institute of Medical Sciences, \\ ${ }^{b}$ Department of Dentistry, Chhindwara. M. P. India
}

\begin{abstract}
Epulis synonymous with congenital granular cell tumor (CGCT) of the new born is an unusual hamartomatous benign lesion arising from either the maxillary or mandibular alveolar ridge, the later being very rare. CGCT is a lesion of unknown histogenesis with a strong predilection for the maxillary alveolar ridge of new born girls. Microscopically the tumor is composed of nests of tightly packed, homogeneous, medium to large sized cells with eosinophilic granular cytoplasm. This case report describes the management of the tumor in a one day old female child presenting with a mass on the mandibular alveolar ridge associated with difficulty in breast feeding and inability to swallow the feed which was affecting her normal physical growth. Two modalities of treatment include conservative and surgical therapy. The lesion was managed by electrosurgical removal and the infant was initially followed up once a month for 3 months and there after every 6 months, for any post operative complications of which non were reported.
\end{abstract}

Key Words: Congenital granular cell tumor, Epulis, Electrocautery, Mandibular alveolar ridge.

Received: 05 February 2020, Accepted: 29 April 2020.

Corresponding Author: Anil Kumar Raichoor, Department of Maxillofacial Surgery, Chhindwara Institute of Medical Sciences (CIMS), Chhindwara. M.P. India, Tel.: +9107162297009, Mobile: +919926421119, E-mail: drrakumar@yahoo. com.

ISSN: 2090-097X, October 2020, Vol. 11, No. 4

\section{INTRODUCTION}

In 1871 a German pathologist Ernst Christian Newman first described congenital granular cell tumor which is also referred to as Epulis and Newman tumor ${ }^{[1]}$. Since then a little over 200 cases of Epulis have been reported in the literature, their size ranging from few millimeters to 9 $\mathrm{cm}^{[2]}$. Congenital granular cell tumor (CGCT) has more predilection towards the maxillary alveolar ridge of new born girls. Exact histogenesis of the tumor is still debated, however microscopically is composed of nests of tightly packed, homogeneous, polygonal to slightly spindled, medium to large sized cells with a eosinophilic granular cytoplasm. The eccentric nuclei may show slight atypia and small nucleoli. Capillary network and overlying stratified squamous epithelium with absence of rete ridges are usually seen ${ }^{[3]}$. Management includes conservative option of observation for spontaneous regression in cases of smaller lesions to surgical excision with electrocautery.

\section{Case Report:}

A one day old female patient (Figure 1) was referred to the Dept of dentistry by consultant obstetrician, for examination of a mass on the lower anterior gingival region. Also the patients mother informed that the infant was unable to breastfeed properly and swallow. On clinical examination a mass measuring approximately $2 \times 1 \mathrm{~cm}$ was seen attached to the mandibular anterior alveolar ridge by broad stalk, it was non fluctuant, non tender, firm in consistency, smooth with normal overlying mucosa. There was no associated lymphadenopathy. The ante natal and post natal history of mother was unremarkable. Complete blood picture and weight of the infant were within normal limits. Since the infant was only 1 day old it was decided to defer the excision of lesion allowing for spontaneous regression and thus assessing difficulty in breast feeding. Infants mother was trained for feeding the child utilizing a palada. The patient was reviewed at regular intervals to observe for any regression of lesion. At one and a half months of follow up slight regression in size of lesion was noticed but difficulty in breast feeding continued affecting the general health of the patient leading to significant parental apprehension. The infant was operated under general anaesthesia, mass was removed using electrocautery and histopathological evaluation was done. Microscopic examination revealed tumor tissue composed of overlying keratinized stratified squamous epithelium, with central zone containing groups of cells with eosinophilic granular cytoplasm and monomorphic, hyperchromatic nuclei scattered against background of fibrocellular stroma features suggestive of CGCT. The post operative period was uneventful and the patient was 
discharged 3 days after surgery. Follow up was done once a month for 3 months (Figure 3) during which the patients milestones were normal. However we advised the mother for further follow up of once every 6 months.

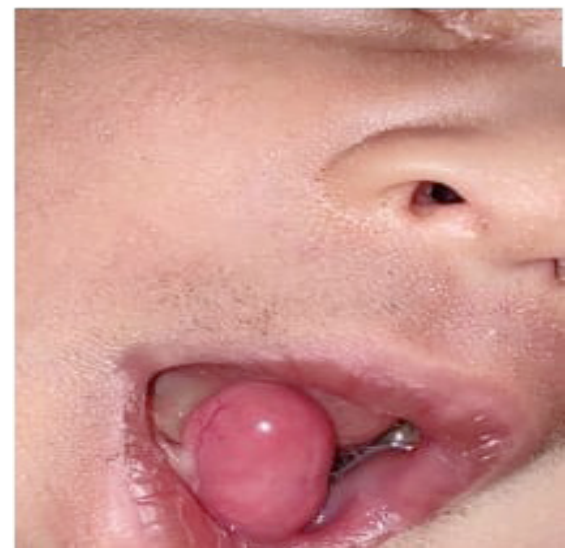

Figure 1: Pre operative photograph of patient shows the lesion on the

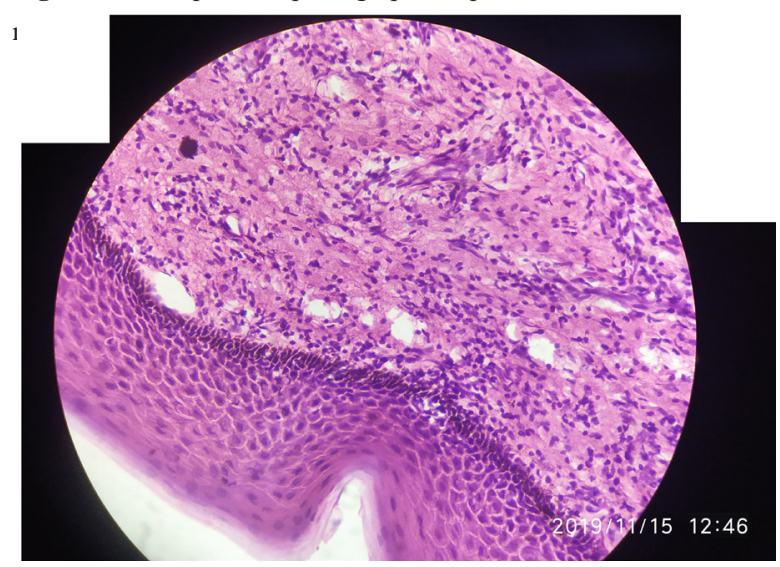

Figure 2: Photo micrograph of the lesions shows tumor tissue composed of overlying keratinized stratified squamous epithelium, with central zone containing groups of cells with eosinophilic granular cytoplasm and monomorphic, hyperchromatic nuclei scattered against background of fibrocellular stroma.

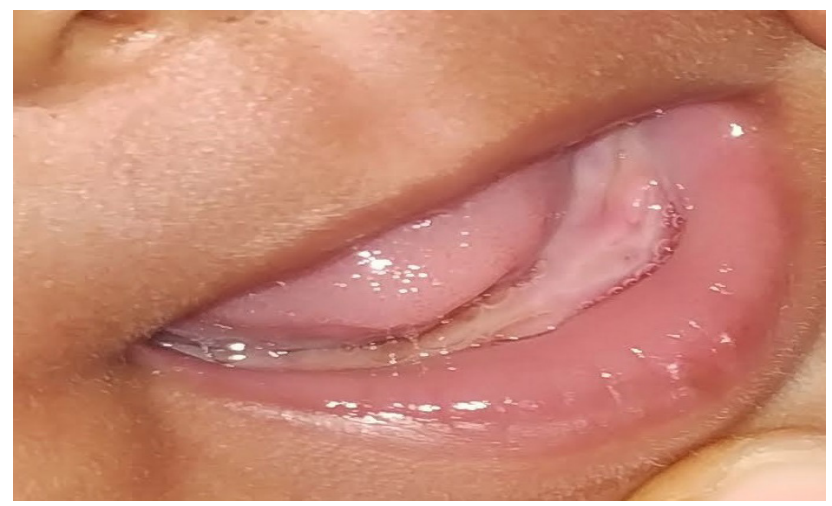

Figure 3: Post operative photograph of patient shows well healed mandibular alveolar ridge.

\section{DISCUSSION}

CGCT'S are benign mesenchymal tumors with predilection towards new born girl's with a female male ratio of $8: 1^{[4]}$. This could be the result of stimulation of intrauterine endogenous hormone. Dash et al. ${ }^{[5]}$ and Lack et al. $^{[6]}$ have reviewed 50 and 21 patients respectively noting multiple commonalities. CGCT has a tendency to develop on the anterior alveolar ridge particularly the maxilla with a three fold increase over that of mandible, which makes our case rare. Most often the tumor is single but in $5-16 \%$ of cases multiple tumors have been reported ${ }^{[7]}$. Differential diagnosis should include teratomas, congenital dermoid cysts, congenital fibrosarcomas, hemangiomas, lymphangiomas, leimyomas, rabdomyomas and lipomas. Histopathologically the tumor usually shows hypervascularity, large granular cells with significant eosinophilic cytoplasm and small basophilic nuclei. Immunohistochemical evaluation include S-100 and Vimentin $^{[8]}$. Management of CGCT is debatable as some authors suggest observation for spontaneous regression in cases of smaller lesions. However tumors that interfere in feeding process should be surgically excised by electrocautery as was done in our case.

\section{CONCLUSION}

CGCT'S are rare benign tumors especially in the mandibular alveolar ridge and early surgical excision with electrocautery is required to prevent feeding difficulties.

\section{CONFLICT OF INTEREST}

The authors declare no conflict of interest.

\section{REFERENCES}

1. Newmann E. Ein fallvon congenitaler epulis. Arch Heilk. 1871: 12: 189 - 190

2. Caravan-Holliday KS, Lawson RA. Anaesthetic management of the new born with multiple congenital epulis. Br J Anaesth. 2004: 93: 742 - 4.

3. Conrad R, Perez CN. Congenital granular cell epulis.. Arch Pathol Lab Med. 2014: 138: 128 - 131.

4. Meetu D, Chayaorka P, Asha A. Congenital granular cell tumor of the alveolar ridge. Indian Journal of Pathology and Microbiology. 2010: 53 (2): 327 - 328.

5. Dash J, SahooP, Das S. Congenital granular cell lesion "congenital epulis" : Report of a case. Journal of Indian Society of Pedodontics and Preventive Dentistry. 2004: 22: 63 - 67. 
6. Lack E, Worsham G, Callihan M, Crawford B, Vawter G. Gingival granular cell tumors of the new born (congenital "epulis") : a clinical and pathologic study of 21 patients. American Journal of Surgical Pathology. 1981: 5 (1): 37 - 46.

7. Yildirim C, Zerener T, Seneiman M, Akyun OM, Altug HA, Cicek AF. Congenital gingival granular cell tumor. A case report. J. Dent Shiraz Univ Med Sci. 2017: 18 (1): 70 - 72.

8. Bianchi P, Araujo VD, Ribeiro J, Santos FP, Araujo NS, Soares A. Multiple congenital granular cell epulis : casr report and immunohistochemical profile with emphasis on vascularization. 2015: 2015 (878192): 5. 